\title{
MUDANÇAS AMBIENTAIS DE ORIGEM ANTRÓPICA E SUA RELAÇÃO COM O ADOECIMENTO HUMANO
}

Lúcia Meirelles Lobão, Bruna Soares de Souza Lima Rodrigues. Mudanças ambientais de origem antrópica e sua relação com o adoecimento humano Revista Saúde Dinâmica, vol. 1, núm. 1, 2019. Faculdade Dinâmica do Vale do Piranga. 


\title{
Mudanças ambientais de origem antrópica e sua relação com o adoecimento humano
}

\author{
Environmental changes of anthropic origin and their relations with human diases
}

\author{
Lúcia Meirelles Lobão ${ }^{1 *}$, Bruna Soares de Souza Lima Rodrigues ${ }^{l}$ \\ ${ }^{1}$ Curso de Medicina, Faculdade Dinâmica do Vale do Piranga, Rua G, 205 - Bairro Paraíso - \\ Ponte Nova - MG - Cep: 35430-302, *lu.mlobao@gmail.com
}

\begin{abstract}
Resumo
A incidência e a distribuição de certas doenças são consequências de mudanças ecossistêmicas e da exposição aos fatores de risco, proporcionados pelo ambiente urbano. O reconhecimento da natureza como um recurso a ser explorado pelo homem, enfatizou a ligação antagônica que o homem estabeleceu com seu ambiente; utilizando das habilidades adquiridas para agredir seu espaço, causando diversos impactos ambientais. Esses vêm se tornando, ao longo da história, mais significativos pela frequência em que ocorrem e a intensidade a qual estão associados. Nesse sentido, este ensaio é uma reflexão sobre os conhecimentos científicos publicados em artigos e livros texto sobre as alterações ambientais e a relação com a saúde humana. As palavras-chave utilizadas para busca foram "adoecimento humano", "saúde coletiva", "saúde ambiental", "desequilíbrios ambientais"+"doenças", "ecologia médica"; nas plataformas Scielo, Pubmed, Google Acadêmico e Science Direct, sem restrição de período e idioma. Além disso, foram utilizados livros texto e literatura cinzenta. As modificações de habitat, as mudanças climáticas e os desastres ambientais estão entre os desequilíbrios que causam múltiplos efeitos na saúde, como doenças infecciosas, transtornos pós-traumáticos e óbito. Desta forma, tornam-se necessárias medidas integrativas que visem abastecer o sistema com informações relevantes sobre quaisquer mudanças nos fatores ambientais que possam proporcionar o adoecimento humano.
\end{abstract}

Palavras-chave: adoecimento humano, saúde coletiva, saúde ambiental

\begin{abstract}
Some diseases are consequences of ecosystem changes and exposure to risk factors, which are results of the urban environment. The use of nature as a resource by man emphasized the antagonistic connection between human being and his environment. He used the acquired abilities to destroy his environment causing diverse impacts. The environmental impacts have become more significant due to the frequency and the intensity they are associated. Thus, the aim of this study is a reflection of scientific knowledge published in articles and textbooks on environmental changes and the relationship with human health. The keywords used were "human illness", "public health", environmental health", "environmental imbalances"+"diseases", "medical ecology" on Scielo, Pubmed, Google Scholar and Science Direct without restriction of period and language. Habitat modifications, climatic changes and environmental disasters are among the imbalances that cause multiple health effects, such as infectious diseases, posttraumatic disorders and death. Like this, integrative issues are needed to provide the system with relevant information on any changes in the environmental factors that may lead to human illness.
\end{abstract}

Keywords: human illness, public health, environmental health 


\section{INTRODUÇÃO}

Doenças como malária, meningite, leishmaniose, dengue, esquistossomose e alterações do trato gastrointestinal ainda atingem milhões de pessoas no mundo (PATZ et al. 2005). No Brasil, por exemplo, apenas em Minas Gerais, foram registrados entre os anos de 2016 e 2018 dois surtos de febre amarela, nos quais 178 casos evoluíram para óbito (SESMG, 2018). Estimase que $25 \%$ das mortes e das doenças globalmente conhecidas estejam associadas aos desequilíbrios ambientais (WHO, 2019), sendo que sua incidência e distribuição são consequências de mudanças ecossistêmicas e da exposição aos fatores de risco, proporcionados pelo ambiente urbano. Assim, o entendimento da relação entre meio ambiente, homem e saúde pode contribuir para o controle de diversas doenças que atingem a humanidade.

A busca da compreensão da relação existente entre o ambiente e a saúde humana surgiu no tratado de Hipócrates, Ares, Águas e Lugares (ÁVILA-PIRES, 2000); e tornou-se emergente na ciência (MEIRA, CARVALHO, 2010; SIQUEIRA-BATISTA,2012; DIASLIMA, 2014; PERES, SEIXA; 2014, QUANDT, et al. 2014). Diferentes disciplinas, tais como Ecologia, Epidemiologia e Ecologia Médica atuam de forma isolada na prevenção das doenças ocasionadas pelos desequilíbrios ambientais, dificultando a atuação holística dos profissionais de saúde. Considerando que os processos ecossistêmicos que afetam a saúde humana são complexos e agem de forma direta ou indireta, a integração das diferentes ciências facilitaria a interpretação e a prevenção de diferentes moléstias.

A relação do homem com a natureza se modificou ao longo da história. No início dos tempos, essa relação era transpassada de mitos, magia e medo, impedindo uma interposição humana catastrófica. A impossibilidade de dominar o meio, direcionou o pensamento humano para uma associação de subjetividade e fatos concretos, permitindo a construção de uma imagem sagrada da natureza. Dessa forma, a concessão das demandas humanas, necessárias a sobrevivência, eram entendidas como dádivas divinas. No entanto, a indispensabilidade de compreender fenômenos, antes desconhecidos, suscitou a necessidade de criar um sentido funcional para a natureza. Assim, com a evolução da espécie humana, o avanço da ciência e a busca por poder e dinheiro, essa concepção de natureza, com poderes absolutos, foi alterada e o homem passou a agir como ser divino. Esse processo foi denominado Revolução Científica, e é caracterizado pelo reconhecimento da natureza como um recurso, um bem a ser apoderado 
pelos homens. No mundo contemporâneo, essa relação tem sido salientada no cenário mundial, considerando a ligação antagônica que o homem estabeleceu com seu ambiente; utilizando das habilidades adquiridas para agredir seu espaço, desconsiderando os diversos infortúnios dessa atitude (DESCARTES, 2005; MONTIBELLER-FILHO, 2008; OLIVA JUNIOR, SOUZA, 2012; NAVES, BERNARDES, 2014).

Pesquisadores evidenciam a existência de três conceitos, que demonstram que o modo como homem enxerga e vivencia a relação com a natureza pode ser consequência da sua compreensão sobre essa ligação. A visão biocêntrica (SÁNCHEZ, 2006), naturalista (REIGOTA, 1991; BEZERRA, GONÇALVES, 2007) ou objetiva (THEYS, 1993) pode ser caracterizada pela equidade entre sociedades humanas e elementos naturais. $\mathrm{Na}$ concepção antropocêntrica (REIGOTA, 1991; SÁNCHEZ, 2006; BEZERRA, GONÇALVES, 2007; REBOLLAR, 2009) ou subjetiva, (THEYS, 1993) a natureza é algo externo aos indivíduos; a relação que se estabelece é entre "sujeitos" (humanos) e "objetos" (fauna, flora, água, ar, etc), sendo os últimos controlados pelos primeiros. Por fim, temos o reconhecimento de uma relação de dependência, inclusão, responsabilidade e equilíbrio entre homem e natureza. Nesse conceito, denominado globalizante (REIGOTA, 1991; CARNEIRO, 1999; BEZERRA, GONÇALVES, 2007; REBOLLAR, 2009) ou tecnocêntrico (THEYS, 1993), a sociedade precisa gerir constantemente sua relação com os elementos naturais, para a manutenção do equilíbrio.

Em um estudo realizado por Rebollar (2009), com 102 alunos dos cursos de Engenharia de Agronomia, Engenharia Ambiental e Zootecnia, de duas universidades da região da grande Florianópolis em Santa Catarina, foi demonstrado que 64\% dos alunos apresentaram uma visão antropocêntrica. A principal desvantagem dessa concepção é o afastamento dos elementos dessa relação (homem e natureza), o que pode culminar na falsa ideia de independência, e assim, justificar a exploração insensata dos recursos naturais pelas sociedades humanas. Em contrapartida, uma pequena minoria, $13 \%$, conceituou o termo "meio ambiente" abordando a visão globalizante. Essa incompreensão pode culminar na dificuldade em elaborar políticas públicas e, principalmente, executar ações que visem a sustentabilidade das atividades humanas.

Entre os serviços prestados pelos ambientes naturais ao homem, podemos citar o fornecimento de alimento, água, madeira, purificação do ar, formação do solo, polinização, regulação do clima e recreação (COMISSÃO EUROPEIA, 2009); todos fundamentais para a 
saúde e para o bem-estar humano. Entretanto, o padrão de exploração atual, que não considera a limitação dos recursos naturais, e a visão antropocêntrica predominante na sociedade, conduzem uma série de mudanças nos ecossistemas e, consequentemente, altera o cenário das doenças que acometem determinada população. As doenças infecciosas, por exemplo, apresentam aumento da incidência decorrente de infraestruturas deficientes, como as más condições de saneamento básico, o excesso de poluição do ar, o derramamento de substâncias tóxicas ou as mudanças climáticas (WHO, 2019). Assim, o presente ensaio traz uma reflexão sobre as mudanças ambientais de origem antrópica e sua relação com o adoecimento humano.

\section{METODOLOGIA}

Trata-se de uma pesquisa bibliográfica do tipo revisão narrativa, classificada como exploratória e de natureza qualitativa. A revisão narrativa busca uma análise crítica da literatura, na qual a seleção dos estudos e a interpretação das informações permite discutir, sob o ponto de vista teórico ou contextual, determinado assunto (ROTHER, 2007). As palavras-chave utilizadas para busca foram "adoecimento humano", "saúde coletiva", "saúde ambiental", "desequilíbrios ambientais"+"doenças", “ecologia médica", utilizando as plataformas Scielo, Pubmed, Google Acadêmico e Science Direct, sem restrição de período e idioma. Além disso, foram utilizados livros texto e literatura cinzenta.

\section{DESENVOLVIMENTO}

\section{Mudanças ambientais e o adoecimento humano}

Para entender o que são mudanças ambientais é necessário definir um ecossistema em equilíbrio ou estável. Segundo ODUM (1988), o desenvolvimento de um ecossistema envolve "mudanças na estrutura de espécies e processos da comunidade ao longo do tempo" até que se atinja o equilíbrio dentro de si mesma e com o ambiente físico, o que é denominado clímax. Assim, o ecossistema estável é aquele no qual o consumo anual da comunidade e a exportação estão equilibrados com a produção. Qualquer alteração deste equilíbrio, seja de origem natural ou antrópica, pode ser considerado uma mudança ambiental. Quando a mudança é artificial ou 
uma perturbação de causa humana, ela é caracterizada como impacto ambiental (SÁNCHEZ, 2013). Segundo a resolução Conama Nº 001/1986, impacto ambiental é:

qualquer alteração das propriedades físicas, químicas e biológicas do meio ambiente, causada por qualquer forma de matéria ou energia resultante das atividades humanas que, direta ou indiretamente, afetam: I- a saúde, a segurança e o bem-estar da população; II- as atividades sociais e econômicas; III- a biota; IV- as condições estéticas e sanitárias do meio ambiente; Va qualidade dos recursos ambientais.

Desta forma, ao longo da história o homem ocasionou diferentes impactos nos ambientes naturais; da floresta para áreas agricultáveis, e destas para o ambiente urbano. A preocupação com os impactos ambientais, que vem se tornando mais significativos, pela frequência em que ocorrem e a intensidade a qual estão associados, aflige estudiosos desde o século passado (LEFF, 2002; SANTOS, COSTA, 2015). Além disso, a incompatibilidade do modelo de desenvolvimento econômico atual e a preservação ambiental têm motivado discussões importantes entre pesquisadores (SÁNCHEZ, 2006; REBOLLAR, 2009). Dentre elas, está a preocupação com as doenças infecciosas ou não infecciosas causadas pelos impactos ambientais, que ocorrem por múltiplos fatores e desencadeiam diferentes consequências na saúde humana.

Doenças infecciosas são aquelas causadas pela "transmissão de um agente patogênico específico para um hospedeiro suscetível” (BONITA, BEAGLEHOLE, KJELLSTRÖM, 2010). Desta forma, elas são provenientes da interação unilateral entre dois seres vivos, na qual há, normalmente, prejuízos para o hospedeiro e benefícios para o agente patogênico, sendo esta relação denominada na ecologia, como Parasitismo (POULIN, 2006). Em geral, as relações de parasitismo são resultado de eventos históricos de coespeciação e possuem extrema complexidade (REY, 2010), sendo que a manifestação da doença no hospedeiro depende de múltiplos fatores, incluindo o desequilíbrio entre a relação parasito-hospedeiro. Então, pode-se concluir que as doenças infecciosas são um produto da interação entre patógeno, hospedeiro e ambiente (PATZ et al, 2000).

Ecossistemas intactos mantém as relações e a diversidade das espécies em equilíbrio, o que geralmente ocasiona uma regulação das doenças. Muitas espécies estão direta ou indiretamente associadas ao ciclo de vida de um patógeno e ocupam um nicho que previne a 
invasão de espécies envolvidas na transmissão de uma doença infecciosa (PATZ et al. 2005). Ainda, alguns agentes patogênicos se desenvolvem em ambientes naturais, como a água, e em outros seres vivos, como vetores, estando, portanto, sujeitos às condições ambientais. Assim, muitas são as doenças infecciosas associadas às mudanças do ambiente e elas veem ocorrendo com certa frequência.

Contudo, as doenças infecciosas não são as únicas associadas as mudanças ambientais. As morbidades não infecciosas são pouco mencionadas, mas possuem grande relevância quando discutimos os reflexos do meio ambiente na saúde e alta incidência dessas enfermidades na população. Assim, o adoecimento humano pode estar associado a múltiplos desequilíbrios ambientais como, modificação de habitat, alterações climáticas, inserção de agentes químicos ou biológicos em ambientes naturais ou desastres ambientais. Cada uma dessas mudanças ambientais e as doenças associadas a elas será foco de reflexão nas próximas discussões desse artigo.

\section{A modificação de habitat}

Entende-se como habitat, o lugar ou a estrutura física, no qual um organismo vive (RICKLEFS, 2003). A redução ou alteração do habitat pode ocorrer devido ao desmatamento, a construção de usinas hidrelétricas, ao aumento da temperatura global com consequente acréscimo das áreas inundadas, aos desastres com barragens de minério, ao aumento das áreas irrigáveis, entre outras. Tais mudanças podem alterar a biodiversidade local e consequentemente as relações ecológicas, podendo, por exemplo, aumentar o número de vetores. Além disso, a diminuição de habitat pode promover a migração de espécies vetoras e reservatórios de patógenos para localidades antes isentas, permitindo, assim, o estabelecimento dessas enfermidades em outras regiões.

Um exemplo dessa conjuntura foi o que aconteceu na cidade de Mesquita, Rio de Janeiro. Segundo pesquisas, a transmissão de Leishmaniose no município pode ter 'VCrelação com o desmatamento ocorrido na região. O desmatamento destruiu o habitat do vetor da doença, o flebotomineo, e dos seus hospedeiros/reservatórios naturais. Esses mamíferos silvestres morreram ou migraram e, consequentemente, o artrópode passou a buscar outras fontes de alimento, elevando a prevalência da doença na região (AMARO et al. 2011). 
Em outro estudo foi encontrado correlação entre o aumento de Hantaviroses e a proporção de área cultivada com cana-de-açúcar no estado de São Paulo (PRIST et al. 2016), Os pesquisadores observaram, através de modelos matemáticos, que entre os aspectos sociais, climáticos e ambientais, o melhor preditor para as infecções de Hantaviroses foi o aumento das áreas agricultáveis com a cana-de-açúcar. Assim como em São Paulo, a incidência de Hantaviroses também esteve associada ao manejo florestal no estado do Paraná. Segundo Silva e Guerra (2016) as notificações da doença no estado ocorre, em sua maior parte, com trabalhadores rurais envolvidos no plantio e manejo de Pinus elliotti e Pinus taeda.

As alterações e reduções de habitat tendem a aumentar. De acordo com a FAO, de 1961 até 2016, as áreas agricultáveis no Brasil aumentaram, aproximadamente, de 150 milhões de hectares para 284 milhões, o que está diretamente associado a redução das matas originais. Assim como a construção de reservatórios para os diferentes usos. Além disso, os processos de urbanização também constroem ambientes diretamente relacionados à propagação de doenças; e o país tem cerca de $86,2 \%$ da sua população em ambiente urbano (FOOD AND AGRICULTURE ORGANIZATION, FAO, 2017). Ainda, o Brasil, devido ao clima e a expansão das áreas agricultáveis, torna-se um hot spot para emergência de doenças infecciosas (NAVA et al., 2017).

Considerando esse cenário, podemos esperar o aumento de mais algumas doenças além dos exemplos já citados acima. As arboviroses (doenças veiculadas por insetos), como malária, febre amarela, filariose e dengue apresentam modificações dos perfis epidemiológicos, o que pode estar relacionado as variações climáticas e a redução da mata em fragmentos muito pequenos, somado ao aumento das áreas inundadas. Além desses, podemos citar, ainda, o aumento do número de casos de esquistossomose, relacionada a construção de canais de irrigação. Essa ação humana favorece o aparecimento dos caramujos nessas regiões, possibilitando o estabelecimento do ciclo biológico do helminto. Dessa forma, o estudo da paisagem é uma estratégia que possibilita traçar perfis de saúde das populações (CONFALONIERI, 2005), impedindo o agravamento dos números de casos notificados e possibilitando a prevenção das doenças.

\section{Mudanças climáticas}


Gases como o dióxido de carbono $\left(\mathrm{CO}_{2}\right)$ e metano $\left(\mathrm{CH}_{4}\right)$ desempenham um importante papel na manutenção do clima terrestre, ao absorverem parte da energia solar que é refletida pela superfície da Terra e transformá-la em calor (processo conhecido como "Efeito Estufa"). Apesar destes gases serem encontrados em pequenas concentrações atmosféricas, são muito ativos, e, portanto, vulneráveis às perturbações antropogênicas. O aumento exacerbado das concentrações de $\mathrm{CO}_{2}$ e $\mathrm{CH}_{4}$, desde a Revolução Industrial, tem sido associado a elevação das temperaturas globais. Estima-se que a emissão total de carbono antropogênico a partir de combustíveis fósseis, desmatamentos e mudanças no uso da terra, variou de 460 a 630 GtC por ano entre 1750 e 2011 (IPCC, 2013), e este aumento pode ter contribuído para aquecer, em média, $0,85^{\circ} \mathrm{C}$ a superfície dos continentes e oceanos no período de 1880 a 2012 (IPCC, 2013). Contudo, as mudanças climáticas incluem, além da alteração da temperatura, a precipitação, o vento e a luminosidade e podem afetar de forma múltipla os sistemas naturais, e dessa forma, a sobrevivência, reprodução e/ou distribuição de patógenos e seus hospedeiros (SHORT, CAMINADE, THOMAS; 2017). Por exemplo, prevalência de insetos é altamente dependente das condições ambientais, como a temperatura e a precipitação.

Desde o ano de 2000, a província chinesa, Anhui, vem passando por uma reemergência de malária. De acordo com o estudo de Gao et al. (2012) o aumento dessa doença vetorial na região está fortemente associado com a temperatura, a precipitação e a umidade do ar. Eles explicam, ainda, que o aumento da malária na província deve-se aos impactos climáticos na taxa de incubação do Plasmodium sp, agente etiológico da malária, e das atividades do seu vetor. Por exemplo, as chuvas fornecem locais extras de reprodução ao mosquito e a umidade moderada afeta sua longevidade, permitindo que o vetor transmita a infecção por um longo período de tempo. No Brasil, associação semelhante foi realizada entre a malária e condições climáticas na Amazônia (WOLFARTH-COUTO; SILVA; FILIZOLA, 2018), quando a doença apresentou maior incidência um mês e meio antes ou depois dos picos de chuva.

Uma outra consequência dessas alterações climáticas é a agudização de seca. No semiárido brasileiro, a escassez de chuva comprometeu a disponibilidade de água em mananciais, açudes e rios, entre 2012 e 2013. Esse processo pode ter contribuído com 210 óbitos, no estado de Alagoas, considerando a distribuição de água contaminada, por caminhões pipa. (RUFINO et al. 2015). Assim como a seca, o aumento dos índices pluviométricos também pode estar relacionado à expansão de morbidades na população humana. O estudo de Fonseca et al. (2015) apontou relação entre a chuva e o nível do rio com a taxa de incidência de diarreia 
na região da Amazônia, região que possui a segunda maior taxa de doenças diarreicas em crianças menores de 5 anos.

Dessa forma, entende-se que as mudanças climáticas podem produzir impactos sore a saúde humana por diferentes vias; de forma direta através das ondas de calor ou eventos extremos, ou indiretamente por alterações no ambiente como a modificação de ecossistemas e de ciclos biogeoquímicos (BARCELLOS et al. 2009). Os eventos extremos, por exemplo, estão associados a mortes por estresse térmico e desastres. Já as mudanças ecossistêmicas podem trazer problemas como aumento da incidência de doenças veiculadas por corpos hídricos, emergência de doenças infecciosas e aumento de vetores.

\section{Poluição por agentes não biológicos}

A poluição consiste em qualquer degradação da qualidade ambiental, e pode ser resultado de fatores físicos, químicos ou biológicos provenientes da atividade humana. Estes fatores, quando em contato com a população, provocam uma série de morbidades que geralmente são negligenciadas pela literatura e pelas políticas de saúde pública. Dentre esses fatores pode-se citar, os agrotóxicos, os metais pesados e gases poluentes.

No início do século XX, um produtor rural era capaz de produzir o suficiente para si e mais quatro pessoas, sendo que o mesmo produtor em 1988 alimentava em média 68 pessoas (PAPINI, 2012). Esse incremento da agricultara ocorreu devido à mecanização, aplicação de insumos químicos como fertilizantes, reguladores de crescimento e agrotóxicos. De acordo com Rigotto et al. (2014) o mercado brasileiro de agrotóxicos expandiu rapidamente entre 2000 e 2014 (190\%), com crescimento maior que o dobro do apresentado pelo mercado global (93\%). E a utilização desses insumos tendem a aumentar com as alterações das políticas de regulamentação do uso de agrotóxicos, realizada no ano de 2018. O uso dos agrotóxicos resulta na presença de seus resíduos ou de seus produtos de degradação nos ambientes edáficos e aquáticos, na comunidade e nos alimentos consumidos (PAPINI, 2012). Essa conduta coloca em risco a saúde da população exposta nas fábricas de agrotóxicos e em seu entorno, na agricultura, nas proximidades de áreas agrícolas, além de todos os consumidores de alimentos contaminados. E, apesar de pouco mencionado na literatura, os óbitos relacionados a intoxicação por agrotóxicos são consideráveis, tendo sido registrado, entre os anos de 2000 e 2009, 2.052 óbitos no Brasil (SANTANA, MOURA, NOGUEIRA, 2013). 
Além dos agrotóxicos, outros componentes químicos decorrentes de uma legislação precária e de uma fiscalização inexistente acabam contaminando os recursos hídricos e a atmosfera. A revisão bibliográfica feita por Pontelli, Nunes e Oliveira (2015) aponta que os tratamentos convencionais de água e esgoto não são capazes, por exemplo, de realizar a remoção completa de substâncias conhecidas como disruptores endócrinos. Tais componentes químicos, produzidos naturalmente ou artificialmente, como os estrógenos, interferem no sistema endócrino; e podem estar associados à obesidade. Desta forma, a população estaria consumindo, constantemente, essa forma de poluente, cujos efeitos, na saúde humana, não foram completamente avaliados.

Desde a Revolução Industrial, os poluentes atmosféricos também causam preocupação à saúde. O artigo de Nardocci et al. (2013), por exemplo, apontou, baseado em séries temporais, que os poluentes dióxido de enxofre e ozônio se relacionam com doenças cardiovasculares e respiratórias na cidade de Cubatão. Sabe-se que Cubatão é um dos pólos industriais mais importantes e complexos do país, tendo sido conhecida nas décadas de 70 e 80 como a cidade mais poluída do mundo em função das grandes emissões industriais

\section{Invasão de agentes biológicos}

Ações antrópicas podem condicionar o estabelecimento acidental de seres vivos em habitats e nichos não naturais. É o caso da introdução de espécies exóticas, migração de espécies ocasionadas por fatores como a redução de habitat, instalação de animais sinantrópicos e dispersão de patógenos através de veículos como o esgoto.

O processo de globalização, bem como o deslocamento de pessoas e cargas, contribui para a quebra de barreiras ecológicas, tendo como uma de suas consequências, a introdução de espécies exóticas. A entrada de uma nova espécie em uma localidade impacta diversos componentes do ambiente invadido, como recursos naturais $\mathrm{e}$ bens humanos e, consequentemente, a saúde, estabelecendo uma relação negativa. Um projeto desenvolvido pela Fundação Oswaldo Cruz apontou que 97 espécies exóticas invasoras afetam a saúde humana no Brasil, sendo 14 vírus, 11 bactérias, 7 protozoários, 8 fungos, 12 helmintos, 7 moluscos, 18 artrópodes e 20 plantas (MINISTÉRIO DO MEIO AMBIENTE, 2006).

O estabelecimento de animais sinantrópicos é um problema de saúde mundial. Sinantrópicos são aqueles seres vivos que se adaptaram a viver junto ao homem, a despeito da 
vontade deste; como exemplo, temos: abelhas, ratos, baratas, aranhas e escorpiões (PAPINI, 2012). Estes organismos causam efeitos diferentes na saúde humana, desde sintomas simples até o óbito. Além dessa questão, os processos de urbanização também estão associados a outro tipo de problema, como a aumento da poluição hídrica. Em Minas Gerais, dados da Fundação Estadual do Meio Ambiente indicam que dos 853 municípios do Estado, cerca de $92 \%$ ainda lançam os esgotos brutos nos corpos d’água. O lançamento de esgoto nos corpos hídricos introduz e aproxima, da população, patógenos causadores de doenças como cólera, febre tifoide, leptospirose, giardíase, amebíase e hepatite infecciosa.

\section{Desastres ambientais}

Entende-se por desastres ambientais o resultado de eventos adversos, naturais ou antrópicos, sobre um território ou ecossistema causando danos humanos, materiais ou ambientais e consequentes prejuízos econômicos, sociais e culturais. No ano de 2015 o Brasil passou por um grande desastre ambiental, provocado pelo rompimento de uma barragem de mineração, que liberou um volume estimado de 34 milhões de metros cúbicos de lama, contendo rejeitos de mineração, e os impactos se estenderam por $650 \mathrm{~km}$ ao longo do rio Doce (FREITAS, SILVA, MENEZES, 2016). Roque, Freitas e Garcia (2018) realizaram uma pesquisa após o destre e encontraram como resultado a incidência de $28,9 \%$ da população amostrada com depressão, 32\% com transtorno de ansiedade e 12\% com estresse póstraumático. Em janeiro de 2019, o cenário se repetiu na região de Brumadinho, evidenciando, novamente, como estes eventos refletem na saúde da população.

Desastres como esses comprometem os serviços de provisão de água e alimentos; alteração dos processos de regulação do clima, devido a destruição da cobertura vegetal e modificação do ciclo da água contribuindo para enchentes no período chuvoso. Tais mudanças proporcionam alteração nos ciclos de vetores e de hospedeiros de doenças como, dengue, Chikungunya, zika, esquistossomose. Além disso, os acidentes com animais peçonhentos tendem a aumentar, considerando a destruição dos habitats e consequente aproximação desses animais com a população urbana. As doenças respiratórias também podem ter a incidência acrescida devido ao ressecamento da lama e formação de grande quantidade de poeira (FREITAS, SILVA, MENEZES 2016). 
Desastres semelhantes a estes, mas de origem natural, são os ocasionados por tsunamis e terremotos. Além dos múltiplos efeitos descritos anteriormente, ainda pouco discutidos pela literatura (REIS, CARVALHO; 2016), está o transtorno de estresse pós-traumático e seus desdobramentos. $\mathrm{O}$ isolamento de comunidades, o comprometimento de heranças culturais e a sensação de insegurança pode agravar o quadro de doenças crônicas (FREITAS; SILVA; MENEZES; 2016), assim como provocar o aumento de casos de depressão, ansiedade e crises hipertensivas. A exemplo destes efeitos, deve-se considerar o aumento de acidentes vascularescerebrais após as enchentes de Santa Catarina em 2008 (XAVIER, et al. 2014) e do acidente de Fukujima no Japão (AOKI, FUKUMOTO, YASUDA, 2012). Além do estresse pós-traumático, a saúde da população também é agravada pela perda do vínculo aos sistemas de atenção básica de saúde. Os danos causados por desastres refletem também aos condicionantes presentes nas áreas atingidas e às ações de saúde, seja no processo de preparação, na reposta à emergência ou na recuperação (MISTÉRIO DA SAÚDE, 2018).

\section{CONSIDERAÇÕES FINAIS}

A Vigilância Ambiental em Saúde refere-se a um complexo de medidas integrativas que visam abastecer o sistema com informações relevantes sobre quaisquer mudanças nos fatores ambientais, que possam interferir na saúde humana. O exercício dessa vigilância visa, assim, promover medidas de prevenção e controle desses elementos de risco, e assim, das doenças a eles associadas. Para isso é necessária uma estruturação compatível aos Sistemas de Informação da Vigilância Epidemiológica e aos bancos de dados de saúde do país, permitindo a tomada de decisão efetiva.

O cumprimento desses propósitos exigiu o desenvolvimento de várias estratégias, dentre as quais: vacinação, controle de vetores, controle da qualidade de alimentos e da água para o consumo humano, além das práticas de educação em saúde, que evidenciam a importância de boas práticas de higiene e hábitos saudáveis.

A organização operacional da Vigilância Ambiental em Saúde pode ser dividida, ao menos em teoria, em elementos biológicos - hospedeiros, vetores e reservatórios - e não biológicos - água, ar, solo e contaminantes, mas isso não deve constituir uma separação entre os domínios, visto a imprescindibilidade da integração. Em relação aos elementos biológicos, 
podemos citar a importância das medidas de vigilância na identificação dos fatores de risco relacionados aos vetores (Anopheles, Aedes aegypti, Culex, Flebótomos e Triatomíneos), hospedeiros/reservatórios (caramujos, cães, gatos, morcegos, roedores, saguis, raposas, suínos, bovinos e aves), e animais peçonhentos (serpentes, escorpiões, aranhas, himenópteras e lepidópteros), e no mapeamento das áreas de risco para essas enfermidades e/ou acidentes. Essas informações permitem o desenvolvimento de medidas e o estabelecimento de ações que visem controlar os índices de ocorrência de sinistros e/ou doenças, como: malária, febre amarela, dengue, leishmanioses, raiva, equinococose, leptospirose, peste, doença de Chagas, e outras.

Considerando os elementos não biológicos, o papel da vigilância ambiental em saúde está relacionado a identificação e monitoramento de fontes de contaminação da água, da atmosfera e/ou do solo, com: vírus, bactérias, parasitos, toxinas, substâncias químicas e/ou radiações ionizantes, que possam afetar a saúde humana. Entre as doenças e agravos que podem ser determinados por fatores ambientais, podemos citar: cólera, febre tifoide, gastroenterites, hepatites virais, helmintíases, protozooses, infecções respiratórias, intoxicações diversas, entre outras.

Conclui-se, portanto, que alterações ambientais estão direta ou indiretamente associadas ao processo de adoecimento humano, e que essas modificações devem ser fiscalizadas e monitoradas, pelos órgãos competentes, a fim de identificar e controlar os fatores de riscos, e assim, as doenças aos quais estão vinculados.

\section{REFERÊNCIAS}

AMARO, R. R. A relação entre o desmatamento e a incidência de leishmaniose no município de Mesquita, RJ. Revista GEOMAE, Campo Mourão, v. 2, n. e.1, p. 245-262. 2011.

AOKI, T.; FUKUMOTO, Y.; YASUDA, S. The Great East Japan Earthquake Disaster and cardiovascular diseases. Europe Hearth Journal, v. 33, p. 2796-2803. 2012.

ÁVILA-PIRES, F. Princípio de ecologia médica. Florianópolis: Editora UFSC, 2000, 328p. 
BARCELLOS, C.; et al. Mudanças climáticas e ambientais e as doenças infecciosas: cenários e incertezas para o Brasil. Epidemiologia e Serviços da Saúde, v. 18, n. 3, p. 285-304. 2009

BEZERRA, T. M. O; GONÇALVES, A. A. C, 2007. Concepções de meio ambiente e educação ambiental por professores da Escola Agrotécnica Federal de Vitória de Santo Antão - PE. Biotemas, v. 20, n. 3, p. 115-125.

BONITA, R.; BEAGLEHOLE, R.; KJELLSTROM, T. Epidemiologia Básica. Editora Nacional, São Paulo, $2^{\text {a }}$ ed. 2010.

CARNEIRO SMC,1999. A dimensão ambiental da educação escolar de $\mathbf{1}^{\text {a a }} \mathbf{4}^{\mathrm{a}}$ séries do ensino fundamental na rede pública da cidade de Paranaguá. Tese de Doutorado da Universidade Federal do Paraná, Brasil, 99pp.

COMISSÃO EUROPEIA. Bens e Serviços ecossistêmicos. 2009. Disponível em: http://ec.europa.eu/environment/pubs/pdf/factsheets/Ecosystems\%20goods\%20and\%20Services/Ecosystem_PT.pdf. Acesso em 19/02/2019.

CONAMA. Resolução nº01/86. Disponível em: http://www.palmares.gov.br/wpcontent/uploads/2018/09/res-conama-01-1986.pdf. Acesso em: 18/11/2018

DESCARTES, R. Discurso do método. Tradução: Enrico Corvisieri. Original, - São Paulo: Convívio. 1637pp. , 2005.

DIAS-LIMA, A. Ecologia Médica: uma Visão Holística no Contexto das Enfermidades Humanas. Revista Brasileira de Educação Médica, v. 38, n. 2, p. 165-172. 2014.

FONSECA; P. A. M. et al. O uso de dados de satélite para estudar a relação entre chuva e doenças diarreicas em uma bacia na Amazônia Sul-Ocidental. Ciências \& Saúde Coletiva. v. 2, n. 3, p. 731-742. 2015.

FOOD AND AGRICULTURE ORGANIZATION. 2017. Disponível em: http://www.fao.org/faostat/en/\#country/21/. Acesso em 07/03/2019.

FREITAS, C. M.; SILVA, M. A.; MENEZES, C. M. O desastre na barragem de mineração da Samarco - fratura exposta dos limites do Brasil na redução de risco de desastres. Ciência e 
Cultura, São Paulo, v. 68, n.3, 2016. Disponível em: http://dx.doi.or/10.21800/231766602016000300010. Acesso em 06/03/2019.

GAO, H-W. et al. Change in Rainfall Drives Malaria Re-Emergence in Anhui Province, China. PLOS, v. 7, n. 8, 2012. Disponível em: http://www.plosone.org. Acessado em : 01/03/2019.

IPCC, Climate Change. The Physical Science Basis. Working Group i Contribution to the IPCC Fifth Assessment Report. 2013.

LEFF, E. Epistemologia ambiental. 2a edição. São Paulo: Cortez. 240pp. 2002

MINISTÉRIO DO MEIO AMBIENTE. Espécies exóticas invasoras: Situação Brasileira. Brasilía, Ministério do Meio Ambiente, Secretaria de Biodiversidade e Florestas, 24pp. 2006.

MINISTÉRIO DA SAÚDE. Desastres naturais e saúde: análise do cenário de eventos hidrológicos no Brasil e seus potenciais impactos sobre o Sistema Único de Saúde. Boletim Epidemiológico. Secretaria de Vigilância em Saúde, v. 49, n. 10, 2018.

MONTIBELLER-FILHO, G. O mito do desenvolvimento sustentável: meio ambiente e custos sociais no moderno sistema produtor de mercadorias. 3. ed. - Florianópolis: Ed da UFSC. 306pp. 2008.

NAVA, A. et al. The impacto of global environmental changes on infectious disease emerge with a focus on risks for Brazil. ILAR Journal, Rio de Janeiro, p. 1-8. 2017. Disponível em: https://academic.oup.com/ilarjournal/advance-articleabstract/doi/10.1093/ilar/ilx034/4745724. Acesso em 14/12/2019.

NAVES, J. G. P.; BERNADES, M. B. J. A relação histórica homem/natureza e sua importância no enfrentamento da questão ambiental. Geosul, Florianópolis, v. 29, n. 57, p 7-26. 2014

NARDOCCI, A. C. et al. Poluição do ar e doenças respiratórias e cardiovasculares: estudo de séries temporais em Cubatão, São Paulo, Brasil. Caderno de Saúde Pública, v. 29, n. 9, p. 1867-1876, 2013.

NEDER RT, 2002. Crise socioambiental: Estados \& sociedade civil no Brasil (1982 - 1998). Annablume, Fapesp, São Paulo, Brasil, 38pp. 
ODUM, E. P. Ecologia. Editora Guanabara, Rio de Janeiro, p. 434, 1988.

OLIVA-JÚNIOR; E. F.; SOUZA, M. I. S. Os impactos ambientais decorrentes da ação antrópica na nascente do Rio Piauí - Riachão do Dantas/SE. Revista Eletrônica da Faculdade José Augusto Vieira, v. 5, n. 7, p. 1983-1285. 2012.

PAPINI, S. Vigilância em saúde ambiental: uma nova área da ecologia. Atheneu Editora, São Paulo, $2^{a}$ edição, p. 120, 2012.

PATZ, J. et al. The potential health of climate variability and change for the United States: executive summary of the reporto $f$ the health sector of the US National Assessment. Environmental Health Perspectives, v. 108, p. 367-376, 2000.

PATZ, J. A. et al. Human health: ecosystem regulation of infectious diseases. In: Hassa, R.; Scholes, R.; Ash, N. Ecosystems and Human Well-being: Current State and Trends. Island Press, Washington. p. 391-415. 2005.

PERES, S. M. P.; SEIXA, S. R. C. As conexões em Saúde e Ambiente: uma abordagem interdisciplinar. Caderno eletrônico de Ciências Sociais, Vitória, v. 2, n. 1, p. 2-18, 2014. Disponível em: https://www.researchgate.net/publication/315469551. Acesso em 01/03/2019.

PONTELLI, R. C. N.; NUNES, A. A.; OLIVEIRA, S. V. W. B. Impacto nas saúde humana de disruptores endócrinos presentes em corpos hídricos: existe associação com a obesidade? Ciências \& Saúde Coletiva, v. 2, n. 13, p. 753-766. 2015.

POULIN, R. Evolutionary Ecology of Parasites, Princeton University Press: $2^{\text {a }}$ edição, 2006.

QUANDT, F. L. et al. Saúde Ambiental e atenção à saúde: construção e ressignificação de referências. Caderno Saúde Coletiva, Rio de Janeiro, v. 22, n. 2, p. 15-157. 2014.

REY, L. Parasitos, o ambiente e o homem. In: Rey L. Bases da parasitologia médica. 3. ed. Rio de Janeiro: Guanabara Koogan, 2010. p. 3-14.

RICKLEFS, R. E. As interações entre as espécies: In: Ricklefs, R. E (org). A Economia da Natureza. Guanabara Koogan, Rio de Janeiro, 6 ${ }^{\mathrm{a}}$ ed., p. 255-267, 2003. 
RIGOTTO, R. M.; PAIXAO E VASCONCELOS, D.; ROCHA, M. M. Uso de agrotóxicos no Brasil e problemas para a saúde pública. Caderno Saúde Pública, v. 30, n. 7, p. 1-3. 2014. Disponível em http://dx.doi.org/10.1590/0102-311XPE020714. Acessado em 27/02/2019.

SÁNCHEZ, L. E. Avaliação de impacto ambiental: Conceitos e métodos. Oficina de Textos, São Paulo, Brasil, 495 p. 2006.

SÁNCHEZ, L. E. Avaliação de Impacto Ambiental: Conceitos e Métodos. Oficina de Textos, São Paulo 2a edição. 495 p. 2013.

SANTANA, V. S.; MOURA, M. C. P.; NOGUEIRA, F. F. Mortalidade por intoxicação ocupacional relacionada a agrotóxicos, 2000-2009, Brasil. Revista Saúde Pública, v. 47, n. 3, p. 589-606, 2013.

SANTOS, T. C.; COSTA, M. A. F. Um olhar sobre a educação ambiental expressa nas diretrizes curriculares nacionais para a educação ambiental. Revista Práxis, v. 3, n. 13. p. 2176-9230 | 2015.

SECRETARIA DE ESTADO DE SAÚDE DE MINAS GERAIS. Febre Amarela Silvestre em Minas Gerais. Boletim Epidemiológico Especial: Secretaria de Vigilância e Proteção à Saúde. Disponível em: http://www.saude.mg.gov.br/component/gmg/story/10625-informeepidemiologico-da-febre-amarela-21-06. Acesso em : 19/02/2019.

SHORT; E. E.; CAMINADE, C.; THOMAS, B. N. Climate Change Contribution to the Emergence or Reemergence of Parasitic Diseases. Infectious Diases: Research and Treatment, New York, v. 10, p 1-7, 2017.

SIQUEIRA-BATISTA, R. et al. Moléstia de Chagas e ecologia profunda: a "luta antivetorial" em questão. Ciências \& Saúde Coletiva, v. 16, n. 2, p. 677-682. 2011.

REBOLLAR, P. M. Educação Ambiental e os termos meio ambiente e impacto ambiental na visão de alunos do ensino superior da região da grande Florianópolis - SC. Biotemas, v. 22, n. 2, p. 173-180, 2009.

REIGOTA, M. O que é educação ambiental. Editora Brasiliense, São Paulo, Brasil, 63pp. 1991. 
THEYS, J. L'environnement à la recherche dúne définition. Notes de méthode de Institut Français de l'Environnement, Paris, França, 46pp. 1993.

WHOLFARTH-COUTO, B.; SILVA, R. A.; FILIZOLA, N. Variabilidade dos casos de malária e sua relação com a precipitação e nível d'água dos rios no Estado do Amazonas, Brasil. Cadernos de Saúde Pública, v. 35, n. 2, p. 1-15. 2019.

WORLD HEALTH ORGANIZATION. Priority environment and health risks. 2019. Disponível em: https;//www.who.int/heil/risks/em/.Acesso em 19/02/2019. 